\title{
Non-specific adsorption of fish immunoglobulin $M$ (IgM) to blocking reagents on ELISA plate wells
}

\author{
W. S. Kim, T. Nishizawa*, M. Yoshimizu \\ Faculty of Fisheries Sciences, Hokkaido University, Hakodate 041-8611, Japan
}

\begin{abstract}
Enzyme-linked immunosorbent assay (ELISA) is a popular technique for quantifiable detection of specific antibodies in warm-blooded animals, but it has not been accepted for detection of fish antibodies because of its low reproducibility, which is due in part to high background optical density (OD) measurements. In the present study, we report that the high background of a fish antibody-detection ELISA resulted from non-specific adsorption of fish immunoglobulin M (IgM) to blocking reagents on the ELISA plate wells. Four fish sera (from rainbow trout Oncorhynchus mykiss, masu salmon O. masou, Japanese flounder Paralichthys olivaceus and koi Cyprinus carpio) were poured into ELISA plate wells pre-blocked with several blocking reagents (skim milk, soybean milk, bovine serum albumin, fetal bovine serum, gelatin and Roche BlockingReagent ${ }^{\circledR}$ ) and then washed out in order to measure the remaining fish IgM on the ELISA plate wells. Significant amounts of fish IgMs (OD absorbance at $492 \mathrm{~nm}$ : 0.3 to 1.1) remained on the ELISA plate wells with no antigenic protein except blocking reagents. The amount of remaining fish IgMs on the ELISA plate wells decreased significantly following treatment of fish sera with skim milk. However, the specific immuno-reactivity of fish IgM was not reduced by such treatment. Thus, we conclude that treatment of fish sera with skim milk is useful in reducing the high background OD often observed in fish IgM detection ELISA.
\end{abstract}

KEY WORDS: Fish serum $\cdot$ Immunoglobulin M $\cdot$ IgM $\cdot$ Adsorption $\cdot$ Antibody detection $\cdot$ Enzymelinked immunosorbent assay $\cdot$ ELISA

\section{INTRODUCTION}

Enzyme-linked immunosorbent assay (ELISA) is a useful quantifiable technique for detection of antigens or specific antibodies, particularly for routine screening involving large numbers of samples requiring high sensitivity, rapidity and low cost. Antibody-detection ELISA is widely used for diagnosis, sero-monitoring and certification of infectious diseases in warm-blooded animals. Several studies using ELISA systems for detection of specific fish antibodies have been reported for aquatic animals as well (Yoshimizu et al. 1992, Dixon et al. 1994, LaPatra 1996, Nishida et al. 1998a, Watanabe et al. 1998, Swain \& Nayak 2003, Okuda et al. 2006). For example, Watanabe et al. (1998) reported successful prevention of vertical transmission of pathogenic viruses by selection of specific pathogen-free spawners, as indicated by results from an antibody-detection ELISA. However, antibody-detection ELISA has not been accepted internationally because the ELISA system for fish antibody detection has problems, such as low reproducibility partly due to high background optical density (OD) caused by non-specific reactions between fish antibodies and antigens (Olesen et al. 1991, Höglund \& Pilström 1995, Knopf et al. 2000, Kibenge et al. 2002, Guo \& Woo 2004). We have experienced similar problems with ELISA systems used for detection of fish antibodies against pathogenic viruses, infectious hematopoietic necrosis virus, viral hemorrhagic septicemia virus, fish nodavirus, lymphocystis disease virus and koi herpesvirus, etc.

In the present study, we report that the high background OD of a fish antibody-detection ELISA resulted from non-specific adsorption between fish antibody and blocking reagents, and that pre-treatment of fish sera with skim milk solution was useful for reducing the background without reducing specific antibody activities. 


\section{MATERIALS AND METHODS}

Sera. Normal fish sera from rainbow trout Oncorhynchus mykiss, masu salmon O. masou, Japanese flounder Paralichthys olivaceus and koi Cyprinus carpio raised in fish farms were used in this study. Antibovine serum albumin (BSA) koi serum was prepared as follows: blood from koi immunized 4 times at $1 \mathrm{wk}$ intervals with $200 \mu \mathrm{g} \mathrm{BSA} \mathrm{fish}{ }^{-1}$ was clotted at $4^{\circ} \mathrm{C}$ overnight and centrifuged at a low speed $\left(2000 \times g_{1}\right.$ $10 \mathrm{~min}$ at $4^{\circ} \mathrm{C}$ ), and the resultant supernatant was collected to use as an anti-BSA koi serum.

Rabbit antisera against rainbow trout, masu salmon, Japanese flounder and koi immunoglobulin M (IgM) were previously prepared in our laboratory by a standard method (Nishida et al. 1998a, 1998b, Okuda et al. 2006, Y. Kokawa et al. unpubl.). Briefly, fish serum was precipitated with $50 \%$ saturated ammonium sulfate and dialyzed with $15 \mathrm{mM}$ Tris- $\mathrm{HCl}(\mathrm{pH}$ 8.0). Fish IgM was purified by chromatography with DEAE cellulose (DE-52, Whatman) and Sepharose 6B (Pharmacia). Purified fish IgM $(250 \mu \mathrm{g})$ was emulsified with Freund's incomplete adjuvant and injected subcutaneously into New Zealand white rabbits. After 4 booster injections at $1 \mathrm{wk}$ intervals, rabbit blood was collected and clotted at $4{ }^{\circ} \mathrm{C}$ overnight to obtain antifish IgM rabbit serum.

Blocking reagents. We used 6 blocking reagents: $5 \%$ non-fat skim milk (Wako), $2 \%$ soybean milk (Marusan), $2 \%$ BSA fraction $\mathrm{V}$ (Wako), $2 \%$ fetal bovine serum (FBS, Gibco), $2 \%$ gelatin (Wako) and 2\% Roche BlockingReagent ${ }^{\circledR}\left(\mathrm{BR}^{\circledR}\right)$. $\mathrm{BR}^{\circledR}$ was dissolved in maleic acid buffer (100 mM maleic acid, $150 \mathrm{mM} \mathrm{NaCl}, \mathrm{pH}$ 7.5), while the other blocking reagents were dissolved in or diluted with phosphate-buffered saline (PBS pH 7.5).

ELISA. Two kinds of 96-well ELISA plates were prepared: the no antigen-ELISA (NoAnti-ELISA) plate and the BSA-ELISA plate. The NoAnti-ELISA plate was prepared by placing $400 \mu \mathrm{l}$ of 6 blocking reagents in each of the 2 wells of the ELISA plate (Greiner), incubating it at $25^{\circ} \mathrm{C}$ for $1 \mathrm{~h}$ and washing the plate wells 3 times with PBS containing $0.05 \%$ Tween 20 (TPBS). For preparation of the BSA-ELISA plate, BSA solution (0 to $100 \mathrm{ng} 50 \mathrm{\mu l}^{-1}$ well $^{-1}$ ) was placed in each of the 2 wells of the ELISA plate and fixed by drying at $37^{\circ} \mathrm{C}$. The ELISA plate wells were covered with $400 \mu \mathrm{l}$ of blocking solution at $25^{\circ} \mathrm{C}$ for $1 \mathrm{~h}$ and washed 3 times with T-PBS.

The ELISA plate wells were treated with $50 \mu \mathrm{l}$ of diluted primary fish antisera with PBS at 1:40 and incubated at $25^{\circ} \mathrm{C}$ for $1 \mathrm{~h}$. The fish IgMs that had reacted on the ELISA plate wells were detected with anti-fish IgM rabbit antiserum (secondary reagent) and with antirabbit immunoglobulin $\mathrm{G}\left(\mathrm{I}_{\mathrm{g}} \mathrm{G}\right)$ swine antiserum (tertiary reagent) conjugated with horseradish peroxidase
(HRP, Dako). The rabbit and swine sera were diluted with PBS at 1:1000 before use. The ELISA plate wells were washed 3 times and incubated with the secondary reagent at $25^{\circ} \mathrm{C}$ for $30 \mathrm{~min}$. After having been washed with T-PBS 3 times, the plate wells were incubated with the tertiary reagent at $25^{\circ} \mathrm{C}$ for $30 \mathrm{~min}$. The ELISA plate wells were then washed again 3 times with T-PBS and finally developed by incubating at $25^{\circ} \mathrm{C}$ for $15 \mathrm{~min}$ with $50 \mu \mathrm{l}$ of phosphate-citrate buffer (100 mM Na $2 \mathrm{HPO}_{4}, 50 \mathrm{mM}$ citric acid) containing $1.0 \mathrm{mg} \mathrm{ml}^{-1} O$-phenylenediamine and $0.03 \% \mathrm{H}_{2} \mathrm{O}_{2}$. After treatment with $2 \mathrm{~N} \mathrm{H}_{2} \mathrm{SO}_{4}$ to stop the development reaction, the absorbance at $492 \mathrm{~nm}\left(\mathrm{OD}_{492}\right)$ was detected using a microplate reader (MTP-300, Corona).

SDS-PAGE and Western blot analyses. BSA $(2.5 \mu \mathrm{g})$ was subjected to sodium dodecyl sulfate polyacrylamide gel electrophoresis (SDS-PAGE) with 10\% polyacrylamide gel under the reducing conditions (Laemmli 1970), and stained with Coomassie brilliant blue. The separated proteins were electro-blotted onto a nitrocellulose membrane by the procedure described by Towbin et al. (1979) for immunostaining with antiBSA koi (primary) serum, anti-koi IgM rabbit (secondary) serum and alkaline phospatase (AP) conjugated anti-rabbit IgG swine (tertiary) serum. The immunostained proteins were visualized with an AP conjugate substrate kit (Bio-Rad) according to manufacturer's instructions.

\section{RESULTS AND DISCUSSION}

As described in 'Materials and methods', normal fish sera from rainbow trout, masu salmon, Japanese flounder and koi were poured into the NoAnti-ELISA plate wells pre-blocked with $5 \%$ skim milk, $2 \%$ soybean milk, 2\% BSA, $2 \%$ FBS, $2 \%$ gelatin or $2 \%$ BR ${ }^{\circledR}$; the plate wells were incubated at $25^{\circ} \mathrm{C}$ for $1 \mathrm{~h}$ and washed out with T-PBS to detect any remaining fish IgM. Remaining rainbow trout IgM was detected at $\mathrm{OD}_{492}$ values between 0.3 and 0.9 (Fig. 1). The same tendency was also observed for masu salmon, Japanese flounder and koi fish sera, which had $\mathrm{OD}_{492}$ values between 0.3 and 1.1 (Fig. 1), while the maximum OD value in the ELISA wells without fish serum was only 0.03. These results showed that significant amounts of fish IgM remained on the NoAnti-ELISA plate wells, even though there was no antigen on those ELISA plate wells. Olesen et al. (1991) previously reported a similar phenomenon for rainbow trout sera and ELISA plate wells blocked with $1 \%$ BSA. These results demonstrate that non-specific reaction of secondary and tertiary antibodies with the blocking reagents did not occur, as indicated by the $\mathrm{OD}_{492}$ value of 0.03 for the control wells without fish serum (Fig. 1). Moreover, 


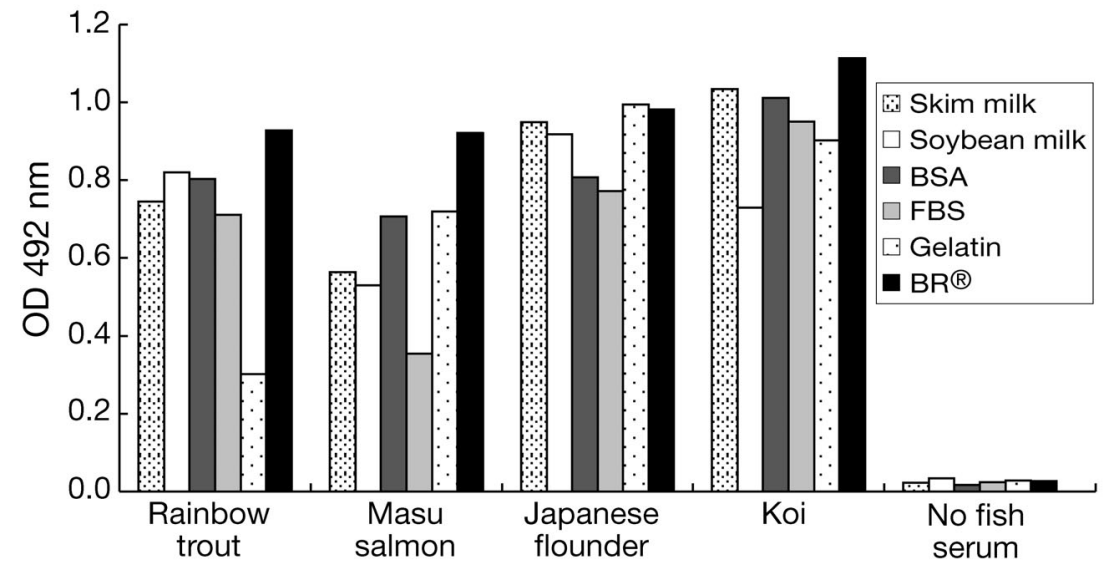

Fig. 1. Non-specific adsorption of fish immunoglobulin $M$ (IgM) to blocking reagents on ELISA plate wells: 4 normal fish sera were poured into NoAnti- (no antigen) ELISA plate wells pre-blocked with different blocking reagents and washed out to measure the remaining fish IgM on the plate wells. OD: optical density; BSA: bovine serum albumin; FBS: fetal bovine serum; BR ${ }^{\circledR}$ : Roche BlockingReagent ${ }^{\circledR}$
These results support the presumption that the detected fish IgMs remained on the NoAnti-ELISA plate wells by nonspecific adsorption to the blocking reagents. Moreover, these results demonstrate that the non-specific adsorption of fish IgM to the blocking reagents can be prevented by competitive blocking of fish sera with $5 \%$ skim milk. A similar phenomenon was observed in other fish species, yellowtail Seriola quinqueradiata, tiger puffer Takifugu rubripes and seven-band grouper Epinephelus septemfasciatus (data not shown). Thus, we speculate that the non-specific adsorption of fish IgMs to blocking reagents may be a common property of fish sera. since the fish antibodies used in this study had almost no chance of recognizing those blocking reagents as antigens, the results indicate that the detected remaining fish IgMs were due to non-specific adsorption of fish IgMs to the blocking reagents on the NoAntiELISA plate wells.

Rainbow trout serum was treated with different concentrations of skim milk and poured into the NoAntiELISA plate wells that had been pre-blocked with $5 \%$ skim milk, to compare the amount of remaining fish IgMs. The $\mathrm{OD}_{492}$ value was 0.9 in the ELISA plate wells with non-treated rainbow trout serum, but it decreased significantly by treatment with more than $0.1 \%$ skim milk, and was less than 0.1 by treatment with $5 \%$ skim milk (Fig. 2A). The skim milk-treated and non-treated rainbow trout sera were then diluted with PBS and poured into the blocked NoAnti-ELISA plate wells. The $\mathrm{OD}_{492}$ values of the non-treated serum decreased gradually with each serum dilution, but those of the treated serum were under the detection limit in any dilution (Fig. 2B). The $\mathrm{OD}_{492}$ values of non-treated masu salmon, Japanese flounder and koi sera were between 0.5 and 1.1 , but those values decreased significantly (to less than 0.12 ) following treatment with $5 \%$ skim milk (Fig. 2C). Next, the combination of the blocking reagents for treatments of fish serum and ELISA plate was investigated. Solutions of $5 \%$ skim milk, $2 \%$ BSA and $2 \%$ FBS were poured into the NoAnti-ELISA plate wells and incubated at $25^{\circ} \mathrm{C}$ for $1 \mathrm{~h}$ to block the wells. After the plate wells were washed out with T-PBS, the skim milk-treated and non-treated sera were poured into the pre-blocked ELISA wells to detect remaining IgM on the wells. The $\mathrm{OD}_{492}$ values of non-treated rainbow trout serum were all above 0.7 , but those of the skim milk-treated serum were all under 0.12 (Fig. 3).
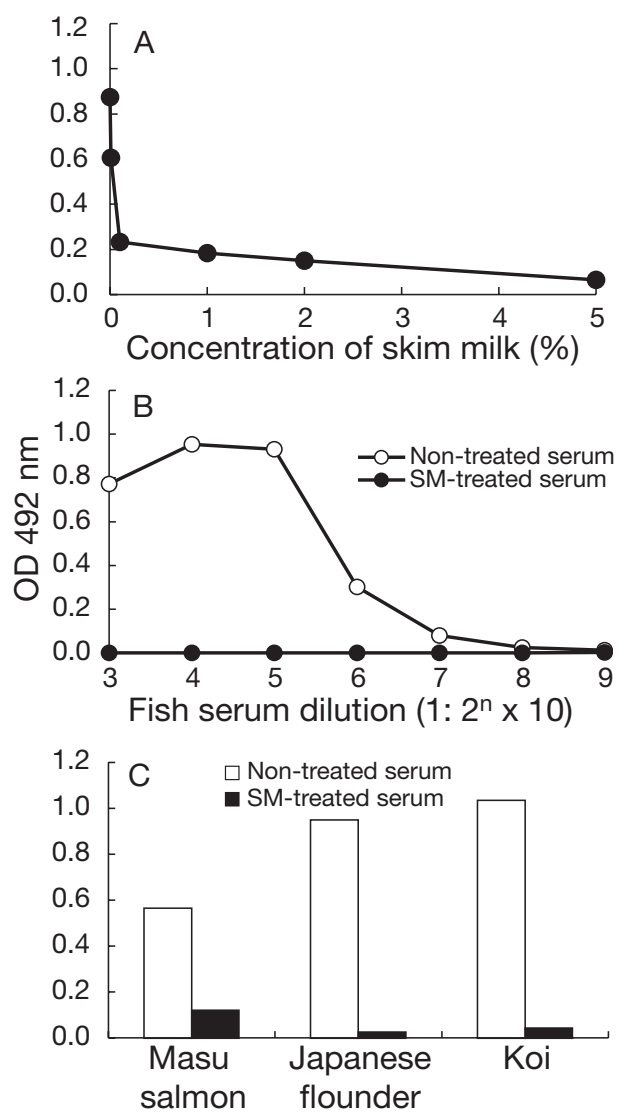

Fig. 2. Reduction of non-specific adsorption of fish immunoglobulin (IgM) by treatment of fish serum with skim milk (SM). (A) Rainbow trout serum treated with different concentrations of SM and poured into the NoAnti-ELISA plate wells pre-blocked with 5\% SM. (B) 5\% SM-treated and nontreated rainbow trout sera were diluted with phosphatebuffered saline (PBS). (C) Reduction of non-specific adsorption of masu salmon, Japanese flounder and koi IgMs after treatment of fish sera with $5 \%$ SM. OD: optical density 


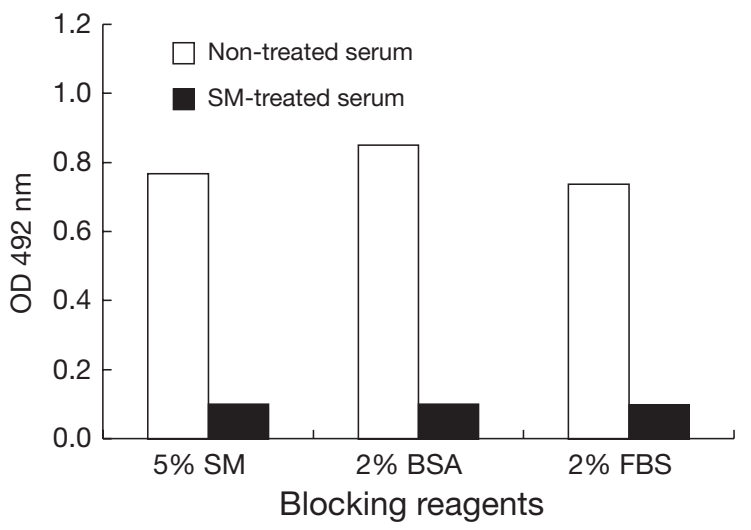

Fig. 3. Reduction of non-specific adsorption of fish immunoglobulin $\mathrm{M}$ (IgM) to heterologous blocking reagents following $5 \%$ skim milk (SM)-treatment of fish serum; treated and nontreated rainbow trout sera were poured into the NoAntiELISA plate wells pre-blocked with 5\% SM, 2\% bovine serum albumin (BSA) and $2 \%$ fetal bovine serum (FBS). OD: optical density
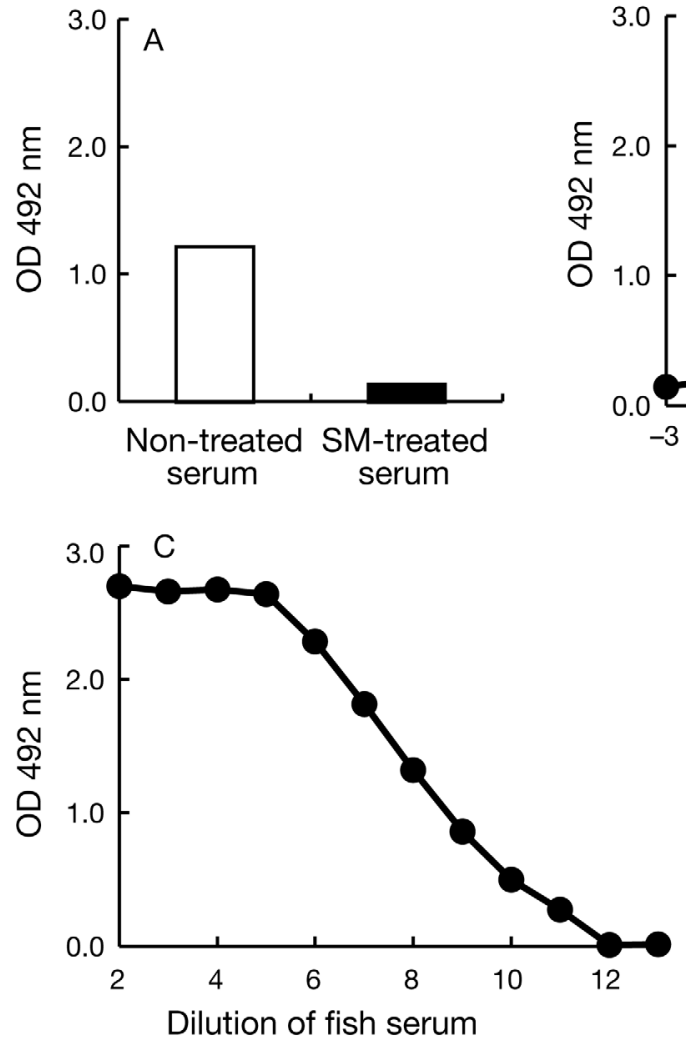

$\left(1: 2^{n} \times 10\right)$
The influence of the competitive blocking of fish sera on the specific reactivity of fish IgM was evaluated. Firstly, anti-BSA koi sera, treated and not treated with $5 \%$ skim milk, were poured into NoAnti-ELISA plate wells pre-blocked with $5 \%$ skim milk and incubated at $25^{\circ} \mathrm{C}$ for $1 \mathrm{~h}$. After the treated and non-treated sera were collected (for future use), remaining koi IgM on the ELISA plate wells was detected, as described in 'Materials and methods'. It was confirmed that nonspecific adsorption of koi IgMs was mostly prevented by competitive blocking with $5 \%$ skim milk, because $\mathrm{OD}_{492}$ values of treated and non-treated anti-BSA koi sera were quite different $(0.14$ and 1.2 , respectively, Fig. 4A). Next, the treated koi serum collected from the NoAnti-ELISA plate wells (Fig. 4A) was subjected to a BSA-detection ELISA to confirm specific reactivity of koi IgM. The treated serum showed $\mathrm{OD}_{492}$ values 0.14 and 0.24 in the BSA-ELISA plate wells containing 0.001 and $0.01 \mathrm{ng}$ BSA per well, respectively (Fig. 4B), and the $\mathrm{OD}_{492}$ values increased as the BSA concentra-

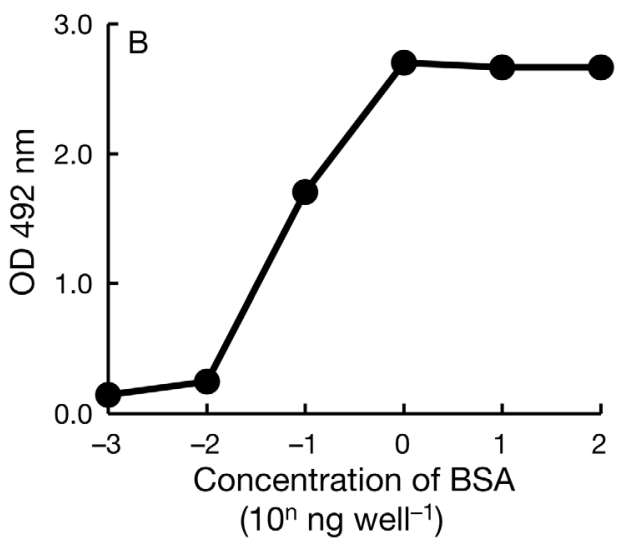

D

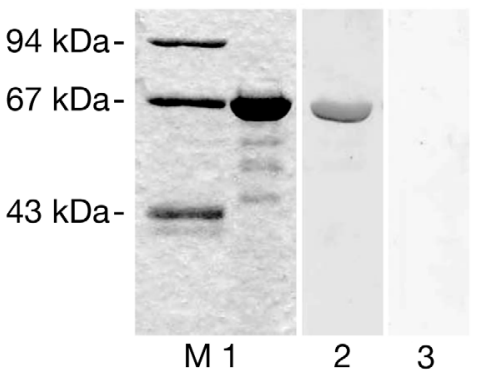

Fig. 4. Influence of fish serum treatment with $5 \%$ skim milk (SM) on specific reactivity of fish immunoglobulin M (IgM). (A) SMtreated and non-treated anti-bovine serum albumin (BSA) koi sera were poured into NoAnti-ELISA plate wells pre-blocked with $5 \%$ SM to compare the amount of remaining fish IgM on the plate wells. OD: optical density. (B) SM-treated koi serum collected from pre-blocked ELISA plate wells was subjected to a BSA-detection ELISA. (C) SM-treated koi serum from pre-blocked plate wells was serially diluted and subjected to a BSA-detection ELISA (100 ng BSA well ${ }^{-1}$ ). (D) Sodium dodecyl sulfate polyacrylamide gel electrophoresis (SDS-PAGE) and Western blot analyses. M: molecular markers; 1: BSA in SDS-polyacrylamide gel stained with Coomassie brilliant blue; 2: immunostained with SM-treated koi serum from pre-blocked plate wells; 3: immunostained with normal koi serum 
tion in the wells was increased, reaching a plateau $\mathrm{OD}_{492}$ of 2.7 in the ELISA wells containing more than $1.0 \mathrm{ng}$ BSA (Fig. 4B). In the BSA-detection ELISA, 2fold serial dilution of the treated serum resulted in a gradual decrease of the $\mathrm{OD}_{492}$ values, as expected (Fig. $4 \mathrm{C}$ ). Moreover, the maximum $\mathrm{OD}_{492}$ value of the BSA-detection ELISA (Fig. 4B,C) was about 2.5 times higher than that obtained with non-specific adsorption of koi IgM (Fig. 4A, non-treated serum). Finally, the collected anti-BSA koi serum was subjected to Western blot analysis. BSA with a molecular mass of $66 \mathrm{kDa}$ was observed in SDS-polyacrylamide gel, and the skim milk-treated serum mono-specifically reacted with BSA, while no reaction was observed between normal koi serum and BSA (Fig. 4D). It was, therefore, assumed that specific reactivity of fish IgM against antigens was not reduced by a competitive blocking of fish serum with skim milk.

In conclusion, an interesting property of fish IgMs was revealed, i.e. the non-specific adsorption of fish IgMs to blocking reagents on the ELISA plate wells. This could be one of the major problems for quantitative detection of fish IgMs using the ELISA system. However, our results show that it is possible to prevent this non-specific adsorption by competitive blocking of fish sera with $5 \%$ skim milk. The degree of non-specific adsorption between fish IgMs and blocking reagents was slightly different among individual fish sera or among fish species. However, we recommend pre-treatment of fish sera with $5 \%$ skim milk for fish antibody detection ELISA because, in our experience, such pre-treatment reduces background OD without inhibiting specific fish IgM immuno-reactivity.

Acknowledgments. This study was partially supported by a Grant-in-Aid from the Ministry of Education, Culture, Sports, Science and Technology of Japan.

\section{LITERATURE CITED}

Dixon PF, Hattenberger-Baudouy AM, Way K (1994) Detection of carp antibodies to spring viraemia of carp virus by a competitive immunoassay. Dis Aquat Org 19: 181-186

Editorial responsibility: Mark Crane, Geelong, Victoria, Australia
Guo FC, Woo PTK (2004) Detection and quantification of Spironucleus barkhanus in experimentally infected Atlantic salmon Salmo salar. Dis Aquat Org 61:175-178

Höglund J, Pilström L (1995) Mechanical isolation and characterization of antigens from adult Anguillicola crassus. Fish Shellfish Immun 5:51-60

Kibenge MT, Opazo B, Rojas AH, Kibenge FSB (2002) Serological evidence of infectious salmon anaemia virus (ISAV) infection in farmed fishes, using an indirect enzyme-linked immunosorbent assay (ELISA). Dis Aquat Org 51:1-11

Knopf K, Naser K, van der Heijden MHT, Taraschewski H (2000) Evaluation of an ELISA and immunoblotting for studying the humoral immune response in Anguillicola crassus infected European eel Anguilla anguilla. Dis Aquat Org 43:39-48

Laemmli UK (1970) Cleavage of structural proteins during the assembly of the head of bacteriophage T4. Nature 227: 680-685

LaPatra SE (1996) The use of serological techniques for virus surveillance and certification of finfish. Annu Rev Fish Dis 6:15-28

Nishida H, Yoshimizu M, Ezura Y (1998a) Detection of antibody against lymphocystis disease virus in Japanese flounder by enzyme linked immunosorbent assay. Fish Pathol 33:207-211

Nishida H, Enokida T, Hiramatsu N, Hara A, Yoshimizu M (1998b) Purification of immunoglobulin M (IgM) in serum of Japanese flounder (Paralichthys olivaceus). Bull Fac Fish Hokkaido Univ 49:157-164

Okuda R, Nishizawa T, Yoshimizu M (2006) Infection-cycles of Renibacterium salmoninarum in hatcheries of masu salmon Oncorhynchus masou by monitoring specific antibodies. Fish Pathol 41:175-178

Olesen NJ, Lorenzen N, Jørgensen PEV (1991) Detection of rainbow trout antibody to Egtved virus by enzyme-linked immunosorbent assay (ELISA), immunofluorescence (IF), and plaque neutralization tests (50\% PNT). Dis Aquat Org 10:31-38

Swain P, Nayak SK (2003) Comparative sensitivity of different serological tests for seromonitoring and surveillance of Edwardsiella tarda infection of Indian major carps. Fish Shellfish Immun 15:333-340

Towbin H, Staehelin T, Gordon J (1979) Electrophoretic transfer of proteins from polyacrylamide gels to nitrocellulose sheets: procedure and some applications. Proc Natl Acad Sci USA 76:4350-4354

Watanabe K, Suzuki S, Nishizawa T, Suzuki K, Yoshimizu M, Ezura Y (1998) Control strategy for viral nervous necrosis of barfin flounder. Fish Pathol 33:445-446

Yoshimizu M, Direkbusarakom S, Nomura T, Ezura Y, Kimura $\mathrm{T}$ (1992) Detection of antibody against Aeromonas salmonicida in the serum of salmonid fish by the enzyme linked immunosorbent assay. Fish Pathol 27:73-82

Submitted: April 12, 2007; Accepted: June 27, 2007

Proofs received from author(s): October 16, 2007 